\title{
Impaired glucose homeostasis in transgenic mice expressing the human transient neonatal diabetes mellitus locus, TNDM
}

\author{
Dan Ma, ${ }^{1}$ Julian P.H. Shield, ${ }^{2}$ Wendy Dean, ${ }^{1}$ Isabelle Leclerc, ${ }^{3}$ Claude Knauf, ${ }^{4}$ Rémy Burcelin, ${ }^{4}$ \\ Guy A. Rutter, ${ }^{3}$ and Gavin Kelsey ${ }^{1}$
}

1Developmental Genetics Programme, The Babraham Institute, Cambridge, United Kingdom. ²Department of Child Health, Bristol Royal Hospital for Children, Bristol, United Kingdom. ${ }^{3}$ Henry Wellcome Laboratories for Integrated Cell Signalling and Department of Biochemistry, University of Bristol, United Kingdom. ${ }^{4}$ Unité Mixte de Recherche 5018, CNRS-UPS, IFR31, Rangueil Hospital, Toulouse, France.

\begin{abstract}
Transient neonatal diabetes mellitus (TNDM) is a rare inherited diabetic syndrome apparent in the first weeks of life and again during early adulthood. The relative contributions of reduced islet $\beta$ cell number and impaired $\beta$ cell function to the observed hypoinsulinemia are unclear. The inheritance pattern of this imprinted disorder implicates overexpression of one or both genes within the TNDM locus: $Z A C$, which encodes a proapoptotic zinc finger protein, and HYMAI, which encodes an untranslated mRNA. To investigate the consequences for pancreatic function, we have developed a high-copy transgenic mouse line, TNDM29, carrying the human TNDM locus. TNDM29 neonates display hyperglycemia, and older adults, impaired glucose tolerance. Neonatal hyperglycemia occurs only on paternal transmission, analogous to paternal dependence of TNDM in humans. Embryonic pancreata of TNDM29 mice showed reductions in expression of endocrine differentiation factors and numbers of insulin-staining structures. By contrast, $\beta$ cell mass was normal or elevated at all postnatal stages, whereas pancreatic insulin content in neonates and peak serum insulin levels after glucose infusion in adults were reduced. Expression of human ZAC and HYMAI in these transgenic mice thus recapitulates key features of TNDM and implicates impaired development of the endocrine pancreas and $\beta$ cell function in disease pathogenesis.
\end{abstract}

\section{Introduction}

Transient neonatal diabetes mellitus (TNDM) is a rare cause of early-onset hyperglycemia in term, newborn infants. Disease onset is usually within the first week of life and is characterized by intrauterine growth retardation, dehydration, and hyperglycemia with associated hypoinsulinemia (1). Although exogenous insulin is required at presentation, remission occurs at an average of 3 months. Affected children have normal glucose homeostasis with normal insulin responses to intravenous glucose challenge, until adolescence or early adult life when the majority develops type 2 diabetes (2), with a loss of the first-phase insulin response signaling the onset of relapse in some cases (3). The clinical features of the disease thus suggest that variations in the ability of the pancreas to produce or to secrete sufficient insulin may be an important underlying cause. Although the possibilities for postmortem analysis of affected subjects are limited, in one case histological analysis revealed seemingly normal islet-cell histology but an absence of insulin-positive cells (4). However, other evidence points to an extrapancreatic defect, with the possibility that insu-

Nonstandard abbreviations used: day postconception (dpc); forkhead box $\mathrm{O} 1$ (FOXO1); glucose transporter type 2 (Glut2); hepatic nuclear factor 3 (HNF3); hydatidiform mole-associated and imprinted transcript (HYMAI); insulin promoter factor-1 (IPF-1); lost on transformation 1 gene (Lot1); neurogenin 3 (Ngn3); P1-derived artificial chromosome (PAC); PACAP type I receptor (PAC1-R); paired box gene-6 (PAX6); pancreatic duodenum homeobox-1 (PDX-1); pancreatic polypeptide (PP); pituitary adenylate cyclase-activating polypeptide (PACAP); pleomorphic adenoma gene-like 1 (PLAGL1); solute carrier family 2, member 2 (Slc2a2); transient neonatal diabetes mellitus (TNDM); zinc finger protein that regulates apoptosis and cell-cycle arrest (ZAC).

Conflict of interest: The authors have declared that no conflict of interest exists.

Citation for this article: J. Clin. Invest. 114:339-348 (2004)

doi:10.1172/JCI200419876. lin resistance plays a further role in the loss of glucose homeostasis and relapse into diabetes in later life (5).

Three genetic anomalies have been described as causing TNDM: paternal uniparental isodisomy of chromosome 6 (6), unbalanced paternal duplication of $6 \mathrm{q} 24$ (the TNDM locus) (7), and maternal methylation anomalies (8). The fact that inheritance of the duplication from the father causes TNDM suggests that the disease is a manifestation of overexpression of an imprinted gene(s). Genomic imprinting is a parent-of-origin-dependent modification that causes differential expression of the two parental alleles in somatic cells $(9,10)$. Two overlapping imprinted genes with silencing of the maternal allele have been demonstrated in the TNDM locus: $Z A C$ (zinc finger protein that regulates apoptosis and cell-cycle arrest) and HYMAI (hydatidiform mole-associated and imprinted transcript) $(11,12)$. Differentially methylated regions are also commonly associated with the control of imprinting (10). Methylation anomalies found in TNDM would be predicted to result in biallelic expression, hence overexpression of ZAC and HYMAI (13-15).

$Z A C$ encodes a zinc finger protein (seven fingers of $\mathrm{C}_{2} \mathrm{H}_{2}$ class) originally identified as a potent factor promoting cell-cycle arrest and apoptosis $(16,17)$. ZAC has been identified independently as a putative tumor suppressor (Lot1 [lost on transformation 1 gene] or PLAGL1 [pleomorphic adenoma gene-like 1]) $(18,19)$, a possible indication of its potency as a cell-cycle regulator. Various in vitro studies have described ZAC as a transcriptional activator, co-repressor, or coactivator (19-21). Although genes directly regulated by ZAC have not been identified definitively, there is evidence that ZAC is involved in the induction of the pituitary adenylate cyclase-activating polypeptide (PACAP) type I receptor (PAC1-R) gene $(22,23)$. PACAP contributes to glucose-stimulated insulin secretion (24) and has been observed to promote the proliferation of $\beta$ cells (25). These 
properties indicate that upregulation of $Z A C$ expression, as predicted in TNDM, could affect pancreatic islet function to cause the disease through one or more possible mechanisms: (a) as a mediator of dysregulated pancreatic $\beta$ cell proliferation and/or death (b) by altering the transcriptional program of the endocrine pancreas or $(c)$ by affecting gene expression in mature $\beta$ cells and hence altering the ability of glucose and other secretagogues to stimulate insulin secretion. The second candidate gene in the TNDM locus, HYMAI, generates an apparently untranslated mRNA of unknown function.

Since the molecular mechanisms leading to the development of TNDM are difficult to study in human subjects, we sought to develop a model of this disease in an experimentally tractable animal. We therefore examined the effects of overexpression of the $T N D M$ locus by creating a transgenic mouse line with a P1-derived artificial chromosome (PAC) containing the entire human $Z A C$ and HYMAI genes. Transgenic mice showed changes in glucose homeostasis whose pattern of onset, remission, and relapse is reminiscent of that observed in humans affected by TNDM. These changes are associated with alterations in the normal development and differentiation of pancreatic islets. This transgenic mouse line thus recapitulates the central features of TNDM and demonstrates the likely sufficiency for the development of the disease of overexpression of genes in the TNDM locus.

\section{Results}

Characterization of transgenic mouse lines. PAC RPCI6-340H11 (Figure $1 \mathrm{~A}$ ) has an insert of $175 \mathrm{~kb}$, which corresponds to about half of the approximately $355-\mathrm{kb}$ TNDM minimal interval and contains the complete $Z A C$ and HYMAI genes and $100 \mathrm{~kb}$ of upstream sequence. The PAC contains the only TNDM candidate genes by virtue of their imprinted status. Eight founders were obtained after pronuclear injection of PAC RPCI6-340H11into fertilized mouse oocytes. Lines from two male founders (TNDM29 and TNDM35) were examined in detail. PCR for markers across the length of the PAC (Figure 1A) indicated that all elements of the PAC were stably integrated and transmitted in these transgenic lines. Southern blotting indicated that lines TNDM29 and TNDM35 possessed 5-10 copies and 2-5 copies, respectively, of the human PAC DNA (data not shown). Initial analysis revealed that TNDM29 transgenic offspring resulting from maternal transmission did not differ from wild-type littermates in respect to blood glucose concentrations (data not shown), whereas offspring generated by paternal transmission showed a defective phenotype (see below), consistent with an imprinting effect on transgene function. Subsequent analysis was therefore performed on transgenic offspring following pater-

\section{Figure 1}

nal transmission, with examination of embryonic stages (14.5 days postconception $[\mathrm{dpc}]$ ), neonates (postnatal day $2-8$ ), juveniles (1.5-2 months old), and adults (6-10 months old). These stages were chosen to represent the different clinical stages of TNDM as infants, teenagers, and adults. TNDM infants present with intrauterine growth retardation, often associated with macroglossia (1). TNDM29 transgenic mice appeared grossly normal and did not differ in body weight from control littermates as newborns, and postnatal growth kinetics were similar (data not shown). Moreover, pancreas/body weight ratios were similar in transgenics and controls at all postnatal stages, and there was no evidence of the macroglossia in transgenic neonates (data not shown).

Tissue distribution of expressed ZAC and HYMAI. Human ZAC expression was examined by semiquantitative RT-PCR using primers that amplify both human and mouse transcripts. PCR products were digested by StyI, which cuts only the human product (Figure 1B). ZAC transcripts were detected in many tissues in TNDM29 neonates, including sites with potential roles in glucose homeostasis, such as brain, pancreas, pituitary, adrenal gland, and liver (Figure 1C). The expression ratio of human $Z A C$ to mouse $Z a c$ RNA was highest in brain, kidney, and adrenal gland (Figure 1C). Levels of expression were higher after paternal transmission of the transgene than maternal transmission (data not shown), again consistent with an imprinting effect. The ratio of human to mouse RT-PCR products was higher in line TNDM29 than in TNDM35 (Figure 1D) in all tissues examined, including pancreas. Analysis with additional primer sets and sequencing RT-PCR products indi-

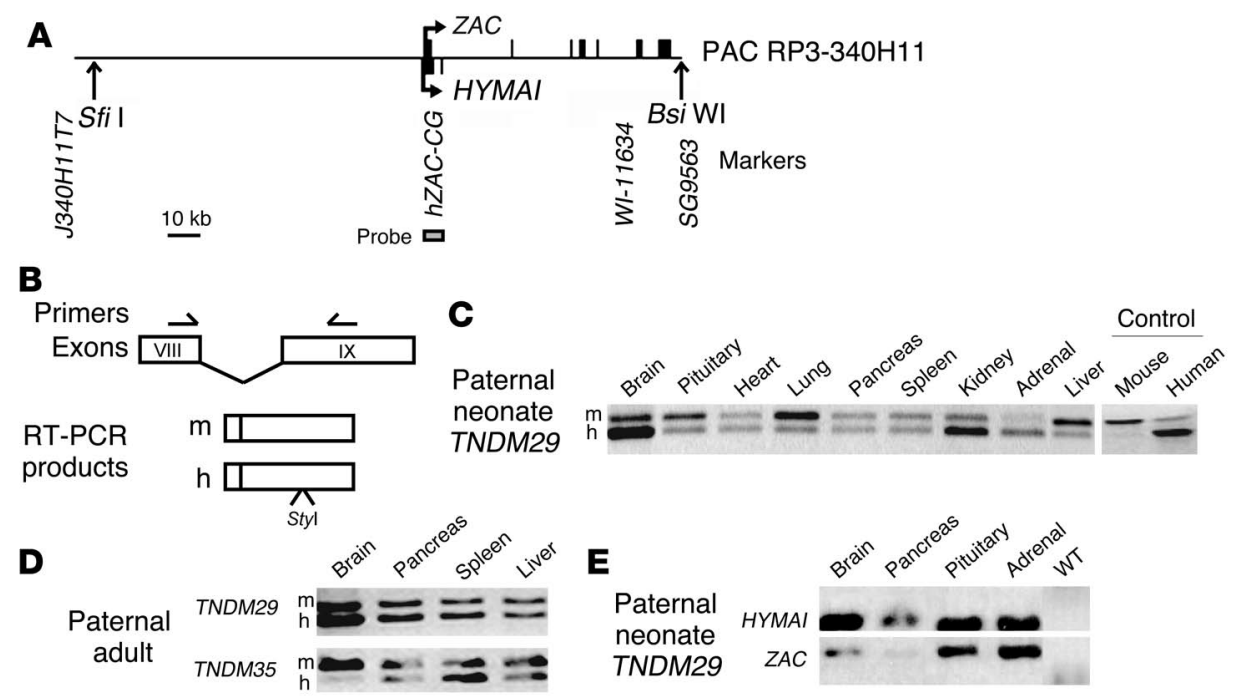

Structure and expression of human TNDM transgene. (A) Human PAC RP3-340H11 contains the entire ZAC and HYMAI genes. The nine exons of ZAC are indicated as bars above the line, the 2 exons of HYMAI below the line; arrows indicate the start sites for and direction of transcription. Restriction sites BsiWI or Sfil for linearization of the PAC for microinjection are indicated. Transmission and integrity of the PAC in transgenic mice was assessed by PCR using the markers indicated; transgene copy number was estimated using the probe indicated. (B) Scheme for the RT-PCR assay for simultaneous detection of human ZAC $(\mathrm{h})$ and mouse Zac $(\mathrm{m})$ mRNAs. RT-PCR products were digested with Styl, which specifically cleaves the human product. (C) RT-PCR of ZAC and Zac in RNA from neonatal tissues of line TNDM29 hemizygous mice after paternal transmission of the transgene. Control lanes are nontransgenic mouse brain RNA (mouse) and human fetal brain RNA (human). (D) RT-PCR of ZAC and Zac RNA in the adult tissues from line TNDM29 and TNDM35 hemizygotes after paternal transmission. (E) RT-PCR of human HYMAl in the neonatal tissues of TNDM29 hemizygotes. Amplification of ZAC RNA in the same CDNA samples was used as an amplification control. 
TNDM29

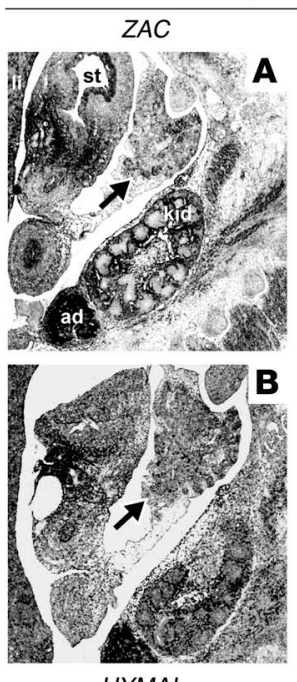

HYMAI

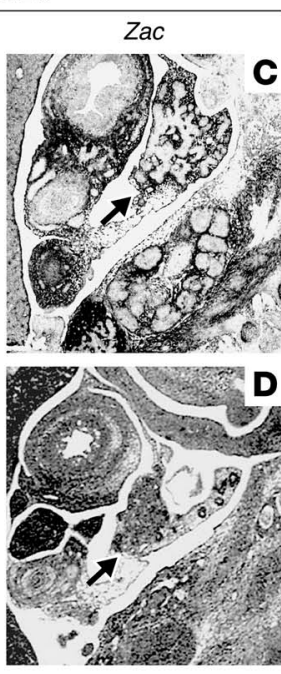

Hymai
WT

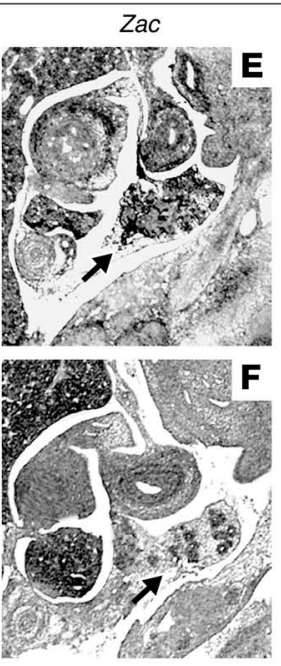

Hymai

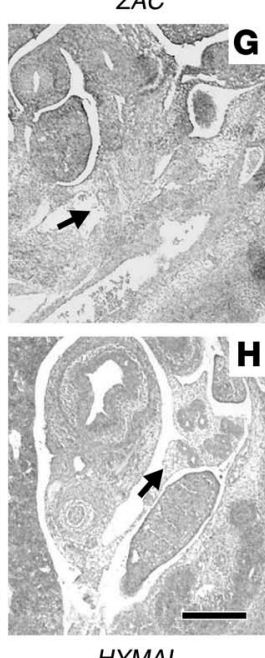

HYMAI
TNM29

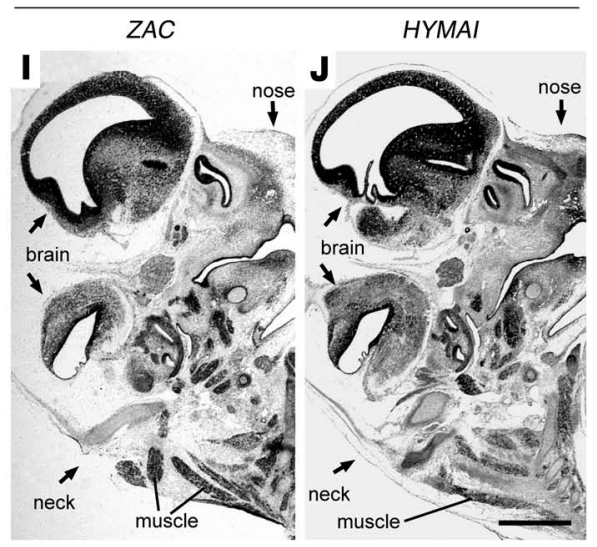

Figure 2

In situ hybridization of human and mouse TNDM locus genes in transgenic embryos. Sagittal sections of viscera from 14.5-dpc TNDM29 transgenic (A-D) and wild-type (E-H) embryos hybridized with human ZAC (A and $\mathbf{G})$, mouse Zac (C and $\mathbf{E})$, human $H Y M A I(\mathbf{B}$ and $\mathbf{H})$, and mouse Hymai (D and F) antisense riboprobes. Arrows indicate pancreas. ad, adrenal gland; kid, kidney; li, liver; st, stomach. Scale bar: 200 um (A-H). Sagittal sections of head and neck from 14.5-dpc TNDM29 transgenic embryos labeled with human ZAC (I) and human HYMAI (J) antisense riboprobes. Note the labeling in brain and muscle. Scale bar: $350 \mu \mathrm{m}$ (I and $\mathbf{J})$.

cated that the coding region of $Z A C$ was intact (data not shown). Human HYMAI expression, examined using primers designed to amplify exon 2 (14), was also detected in brain, pancreas, pituitary, and adrenal gland of TNDM29 neonates (Figure 1E).

Expression of human ZAC and HYMAI was further examined by in situ hybridization in TNDM29 embryos using specific antisense and control sense riboprobes. Widespread expression of $Z A C$ was detected in embryos at $14.5 \mathrm{dpc}$, especially in the nervous system, endocrine system, including pancreatic ducts, pituitary, adrenal glands (Figure 2), and tissues such as liver and muscle involved in glucose homeostasis, as well as tongue (not shown). The expression pattern of HYMAI was generally similar to that of $Z A C$ but with more marked expression in liver. In embryos from line TNDM35, $Z A C$ expression was much weaker (data not shown). When compared with mouse $Z a c$ on adjacent sections, most of the expression sites were similar, except that human ZAC and HYMAI/Hymai were detected in pancreatic ducts, whereas mouse $Z a c$ was detected only in nonductal structures of the pancreas (Figure 2, A and C). ZAC was also present in the epithelium of gut (Figure 2A).

The expression of $Z A C$ and $H Y M A I$ was examined next in postnatal pancreata. In neonates, human $Z A C$ expression was clearly observed in islets and more weakly in exocrine cells (Figure 3C). In contrast, expression of the endogenous mouse $Z a c$ was very weak in islet $\beta$ cells but stronger in the exocrine pancreas (Figure 3, E and G). Human HYMAI and mouse Hymai were expressed similar to $Z A C$ and $Z a c$ in neonates (Figure 3, D, F, and H). Pancreatic islet expression in TNDM29 transgenics continued into adult stages (Figure 3, A and B).

Glucose homeostasis in TNDM transgenic mice. Blood glucose concentrations were found to be significantly elevated in TNDM29 neonates but not in juvenile nor adult TNDM29 mice (Figure 4A). Elevated blood glucose levels were not detected in transgenic neonates of line TNDM35. Since the latter animals expressed lower levels of genes in the TNDM locus (see above), these findings are consistent with a gene dosage-dependent phenotype. Thus, all subsequent analyses were therefore carried out on TNDM29 mice.

Total pancreatic insulin content was significantly lower in TNDM29 neonates compared with control mice (Figure 4B), whereas there was no significant difference in this parameter in juvenile and adult transgenic mice compared with wild-type animals (Figure 4B). However, plasma insulin levels were not significantly different in neonatal, fasted juvenile, or adult TNDM29 mice with respect to controls (Figure 4C).

Islet function was examined in vivo by intraperitoneal glucose tolerance tests. Reduced glucose tolerance was observed in TNDM29 neonates and older adults but was not apparent in juveniles (Figure 5, A-C). Serum insulin levels, monitored 30 minutes after glucose challenge, were also lower in older adult transgenic mice than in controls (Figure 5F). Although we detected no difference in mean serum insulin level in neonatal transgenics versus controls, the higher blood glucose level in these transgenic neonates indicated that there was a defective insulin secretory response. Insulin tolerance tests revealed an anomalous response in adult TNDM29 mice, with a more rapid return to higher blood glucose levels by 45 minutes after challenge with insulin, whereas juvenile TNDM29 mice displayed a normal response (Figure 5, H and I). However, and as shown in Figure 5J, euglycemic hyperinsulinemic clamps demonstrated identical insulin sensitivity in the older TNDM29 animals and wild-type littermates. Similarly, the rate of insulin-stimulated glucose decrease was identical in neonatal TNDM29 mice and controls (Figure 5G).

We next determined whether the apparently abnormal response to elevated glucose levels of islets in vivo might be reflected in deficient insulin secretion in isolated islets. Islets were isolated from pancreata from TNDM29 mice and control littermates, and cultured overnight prior to insulin secretion assays. No significant difference was apparent in the release of insulin at either $3 \mathrm{mM}$ or 
TNDM29
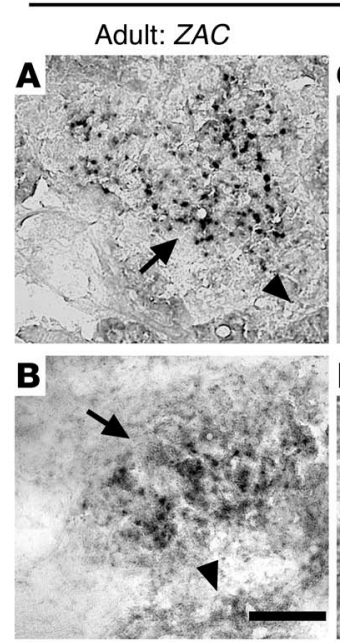

Adult: HYMAI
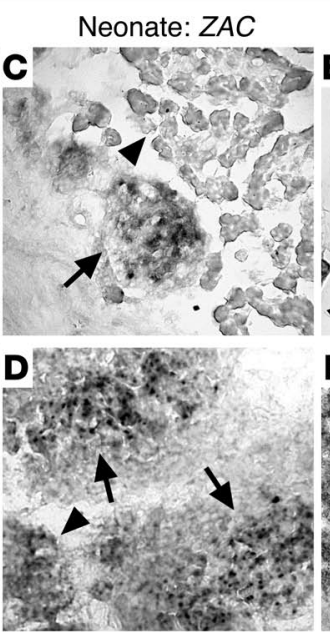

Neonate: HYMAI
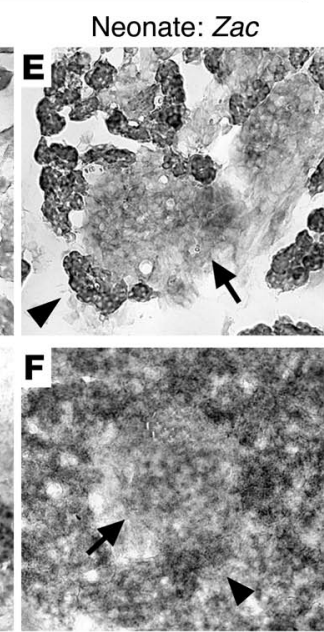

Neonate: Hymai

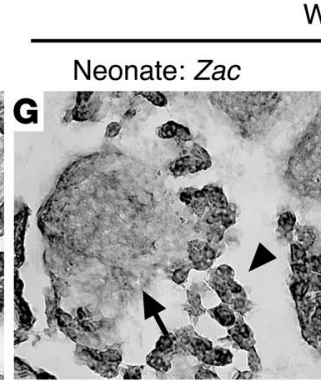

WT
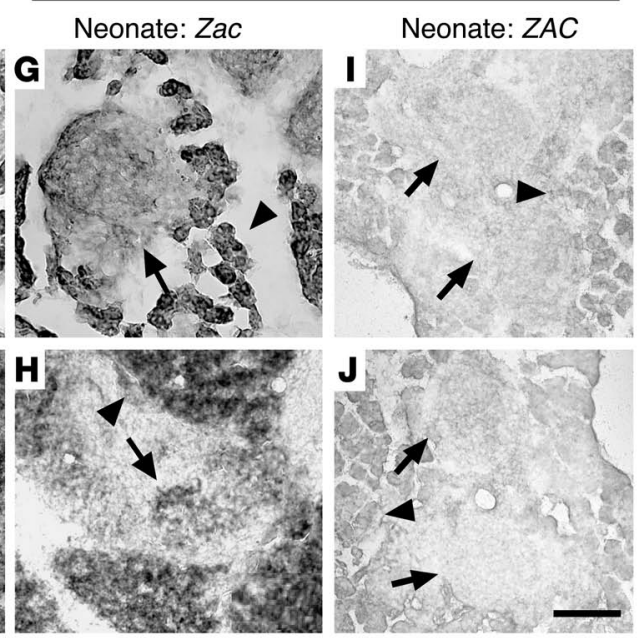

Neonate: Hymai

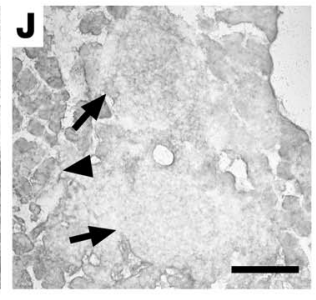

Neonate: HYMAI

\section{Figure 3}

In situ hybridization of human and mouse TNDM locus genes in pancreatic islets. Cryostat sections of pancreas from TNDM29 (A-F) and wildtype (G-J) mice of the indicated postnatal ages hybridized with antisense probes for human ZAC (A, C, and I), mouse Zac (E, G), human HYMAI $(\mathbf{B}, \mathbf{D}$, and $\mathbf{J})$ and mouse Hymai $(\mathbf{F}$ and $\mathbf{H})$. Arrows indicate pancreatic islets; arrowheads indicate exocrine parts. Note that the labeling for human ZAC and HYMAI is heavier in islets and weaker in the exocrine pancreas (A-D), whereas the opposite is true for Zac and $H y m a i(\mathbf{E}-\mathbf{H}) .(\mathbf{I}$ and $\mathbf{J})$ Hybridization of human ZAC and HYMAI probes to nontransgenic sections as negative control. Scale bars: $70 \mu \mathrm{m}(\mathbf{A}$ and $\mathbf{B}) ; 90 \mu \mathrm{m}(\mathbf{C}-\mathbf{J})$.

$17 \mathrm{mM}$ glucose in TNDM29 versus control islets in neonatal (day 2 postnatal) mice $(P>0.1$; Figure $6 \mathrm{~A})$, and juvenile and adult mice (data not shown). By contrast, islets from TNDM29 neonatal mice were more responsive to stimulation with a low level of PACAP $(0.1$ $\mu \mathrm{M})$ at $17 \mathrm{mM}$ glucose $(P<0.05$; Figure 6B).

Dynamic changes in $\beta$ cell mass: morphometric and developmental analysis of the endocrine pancreas. To determine whether the above changes in islet function might be due to alterations in $\beta$ cell development or number, we performed morphometric analysis of the pancreata. H\&E staining of sections from TNDM29 transgenic mice and normal littermates showed normal islet morphology and $\beta$ cell diameter $(P=0.94$; Figure $7, A$ and $B)$. However, the total volume density of insulin-positive structures (which equates to $\beta$ cell mass, given similar pancreatic volumes; see Methods) in TNDM29 mice compared with controls varied during fetal and adult life (as discussed below). At $14.5 \mathrm{dpc}$, insulin-positive structures were present at a lower density in pancreata from transgenic embryos (Figure 8, A, B, and I). Glucagon-positive structures were also less abundant (Figure 8, C, D, and I), as were somatostatin and pancreatic polypeptide (PP) (Figure 8 , E-I), suggesting a general impairment of endocrine islet development in TNDM29 embryos. In contrast, immunohistochemical analysis of the pancreas from neonatal, juvenile, and older adult mice did not show obvious differences in staining intensity for insulin in transgenic versus wild-type controls (Figure 7, C-H), and the average size of islets was not significantly changed $(P>0.05)$. In neonates, in which the endocrine compartment forms a large proportion of the total pancreas (26), the density of insulin-positive structures was similar in TNDM29 transgenic and control pancreata (Figure 7, C, $\mathrm{D}$, and I), indicating a marked increase compared with the embryonic stage. Moreover, at the juvenile stage, islet density was significantly greater than in controls (Figure 7, E, F, and I). In adult transgenic pancreata, islet density was not significantly different between TNDM29 mice and controls, suggesting a relatively greater decline in TNDM29 islet mass during adult life (Figure 7, G-I). A significant increase in the occurrence of glucagon-positive cells within the islet core of juvenile transgenic mice was also noted (Figure 7, J-L).
A

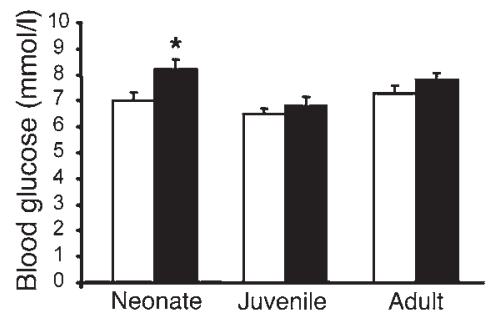

B

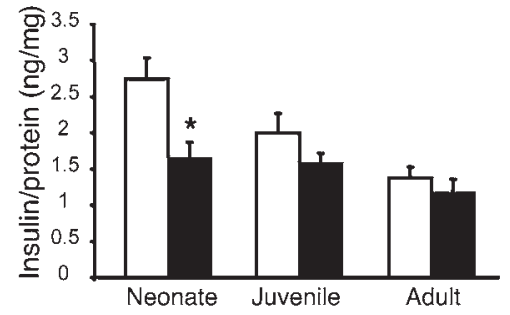

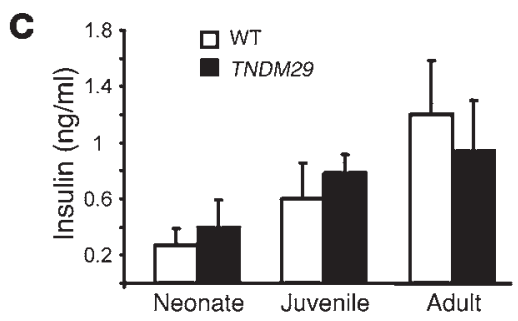

Figure 4

Blood glucose, pancreatic insulin content, and serum insulin in TNDM29 mice. (A) Whole-blood glucose concentrations in mice at the indicated ages. (B) Total pancreatic insulin content. (C) Serum insulin concentration. Juvenile and adult measurements were performed on fasted animals. All results are expressed as mean \pm SEM $(n=6-12) ;{ }^{*} P<0.05$ transgenic versus wild-type control group by unpaired, two-tailed Student's $t$ test and Mann Whitney $U$ test. 

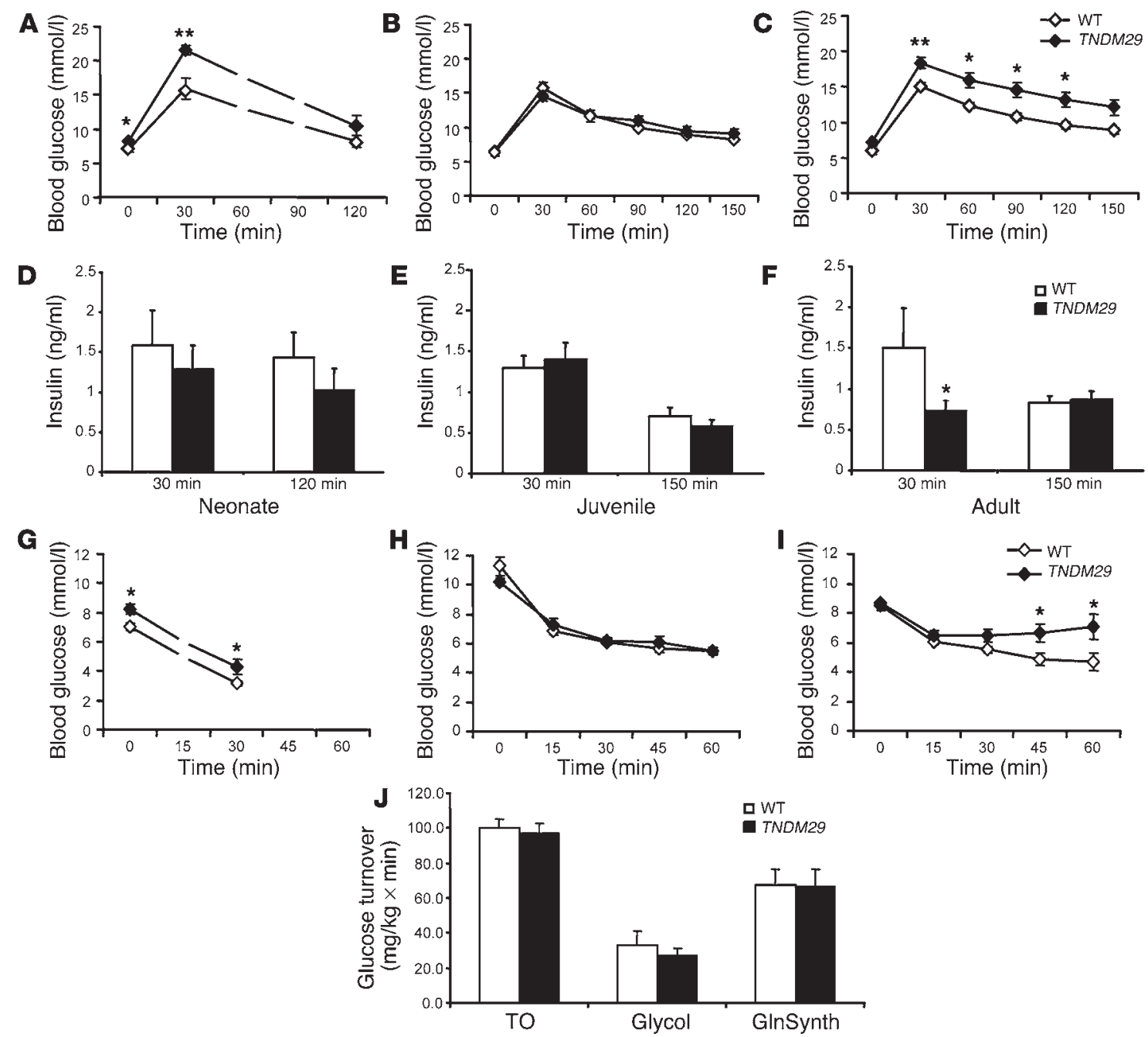

Figure 5

Glucose and insulin tolerance in TNDM29 mice. Glucose tolerance tests (A-C): glucose concentration determined in whole blood at the indicated times following intraperitoneal injection of glucose in neonate (A), juvenile (B), and adult (C) TNDM29 and wild-type mice. Serum insulin concentrations (D-F) at the indicated time points of the glucose tolerance test in neonates (D), juveniles (E), and adults (F). Insulin tolerance tests (G-I): glucose concentration determined in whole blood at the indicated times following intraperitoneal injection of insulin in neonates (G), juvenile (H), and adult (I) TNDM29 and wild-type mice. Euglycemic hyperinsulinemic clamp studies in TNDM29 and wild-type mice (J): whole-body glucose turnover rate (TO), whole-body glycolysis rate (Glycol) and whole-body glycogen synthesis (GlnSynth) during the test are shown. All results are expressed as mean \pm SEM $(n=12-20$, in more than 3 separate experiments, except for the clamp studies, where $n=5-6)$. ${ }^{*}<0.05$, ${ }^{* *} P<0.01$ transgenic versus control group by unpaired, two-tailed Student's $t$ test and Mann Whitney $U$ test, as appropriate.

To investigate the possible basis for the early deficit in endocrine pancreas development, islet progenitor markers and regulators of pancreatic development were examined by immunohistochemistry in sections of 14.5 -dpc embryos. The staining of pancreatic duodenum homeobox-1 (PDX-1) in ductal structures was significantly weaker in transgenic than control pancreas (Figure 9, A, B, and G), and the abundance of positively labeled neurogenin 3 (Ngn3), and paired-box gene 6 (PAX6) nuclei was also reduced (Figure 9, C-F, and $\mathrm{H}$ ).

\section{Discussion}

Glucose bomeostasis and $\beta$ cell function in TNDM locus transgenic mice. The key aim of this study was to determine the mechanisms through which overexpression of the TNDM locus may lead to TNDM. We have thus focused on glucose homeostasis and development of the endocrine pancreas in transgenic mice overexpressing the TNDM locus. We show that paternal transmission of this locus results in hyperglycemia in neonates and impaired glucose tolerance in older adults. By contrast, these parameters were normalized in younger (6- to 10 -week-old) animals, a phenomenon reminiscent of the remission from diabetes seen in children around 3 months of age (1). Moreover, pancreatic insulin content was reduced in neonatal TNDM29 versus control mice, and these animals displayed an insulin secretory deficiency indicated by unaltered serum insulin levels in the face of hyperglycemia. However, islets from these animals tested in vitro displayed unaltered insulin secretion in response to glucose stimulation. On the other hand, glucose-stimulated insulin secretion was reduced in vivo in older TNDM29 adult mice, showing a return to impaired $\beta$ cell function. 

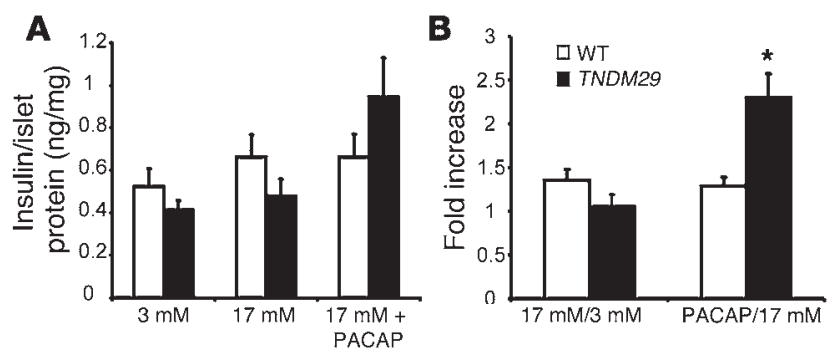

Figure 6

Insulin secretion from isolated pancreatic islets. Insulin secretion was measured in islets isolated form neonatal pancreata (postnatal days $2-3, n=10-15$, in 3 separate experiments). Islets were cultured overnight in $11 \mathrm{mM}$ glucose, and then insulin secretion was determined after 25 minutes' treatment in $3 \mathrm{mM}$ glucose, $17 \mathrm{mM}$ glucose, or $17 \mathrm{mM}$ glucose plus $0.1 \mu \mathrm{M}$ PACAP. Results are presented as nanograms of insulin secreted per milligram total islet protein $(\mathbf{A})$ and as fold increase in insulin secretion (B).

In an effort to understand the underlying causes of pancreatic islet dysfunction, we studied the development of the endocrine pancreas in utero in TNDM29 mice. By 14.5 dpc in mice, the endocrine pancreas has started to develop, although islets are not yet fully formed $(27,28)$. At this stage, the pancreata of TNDM29 mice displayed a significant reduction in all four endocrine cell types. However, a remarkable catch-up was then apparent in the volume density of insulin-positive structures by 3-5 days after birth, indicating a higher proliferation rate of $\beta$ cells in TNDM29 pancreas late in gestation and into the neonatal period, consistent with the wave of neogenesis of $\beta$ cells (29). Nevertheless, total pancreatic insulin content remained lower in TNDM29 neonates compared with controls, possibly because the newly proliferated $\beta$ cells in the transgenic animals may be less well differentiated and able to respond to glucose with the release of insulin. These data indicate that both decreased insulin synthesis and defective insulin secretion from a normal total islet $\beta$ cell mass leads to inadequate insulin release in TNDM29 mice.

In contrast to neonates, juvenile TNDM29 mice displayed a significantly elevated volume of insulin-positive structures (and thus $\beta$ cell mass) but normal pancreatic insulin content. However, there were no differences in these parameters between older adult TNDM29 and control mice. The attainment of a $\beta$ cell volume density nearly twice that of wild-type littermates would appear to be necessary to achieve normoglycemia during the remission phase of the disease in juvenile animals. The significantly greater $\beta$ cell mass in juvenile transgenic mice was an unexpected finding and suggests that a similar expansion in insulin secretory capacity and/ or improvement of other regulatory factors may contribute to the remission from neonatal diabetes seen in the human. Although the mechanisms underlying this apparent surge in $\beta$ cell growth are unknown, it should be noted that $\beta$ cell size was not increased in juvenile versus neonatal TNDM29 mice. The increase in $\beta$ cell mass would thus appear to represent an increase in $\beta$ cell number, reflecting either enhanced neogenesis, replication, or decreased apoptosis. One possibility is that $\beta$ cell proliferation (30), or a decrease in apoptosis (31), might be driven by the neonatal hyperglycemia or changes in the expression of developmental regulators including PDX1, Ngn3, and PAX6. Nevertheless, this compensatory expansion of $\beta$ cell mass could not be sustained throughout life, as the total $\beta$ cell volume was not increased compared with controls in

\section{Figure 7}

Immunohistochemical and morphometric analysis of postnatal pancreata. H\&E staining of paraffin-embedded pancreas sections from juvenile wild-type (A) and TNDM29 littermates (B). Insulin immunohistochemistry at the indicated ages in wild-type (C, E, and G) and TNDM29 (D, F, and H) littermates. Volume density (I) for insulin-positive structures at the indicated ages (the embryonic data from Figure 8 are included for comparison; $n=5$ pancreata per group). Representative islets stained for glucagon from juvenile wild-type (J) and TNDM29 pancreata (K) and (L) measure of proportion of islets showing infiltration of glucagon-positive cells (as defined in Methods; $n=5$ pancreata per group). Results are expressed as mean \pm SEM; ${ }^{*} P<0.05{ }^{* *} P<0.01$ transgenic versus control group by unpaired, twotailed Student's $t$ test. Scale bars: 50 $\mu \mathrm{m}$ (A and B); $200 \mu \mathrm{m}$ (C-H); $60 \mu \mathrm{m}$ ( $\mathbf{J}$ and $\mathbf{K})$.

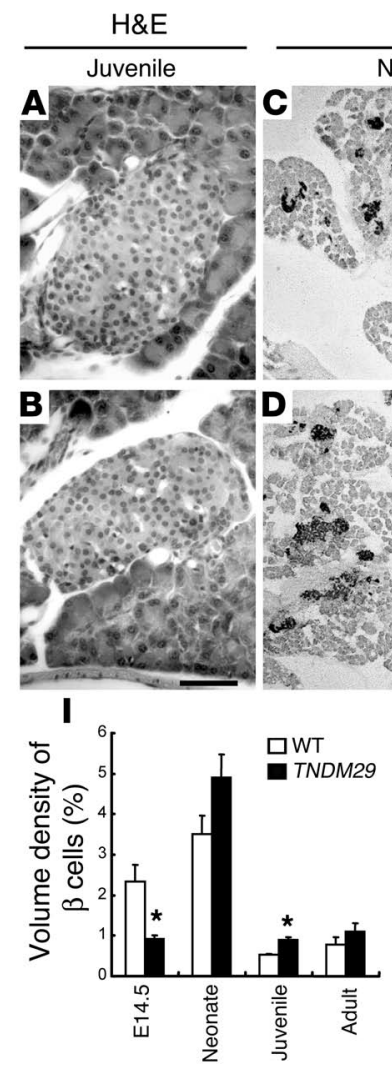

Neonate

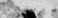

Glucagon
Insulin

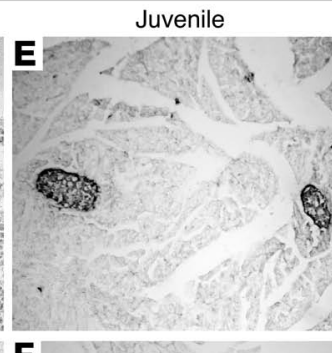

$\mathbf{F}$
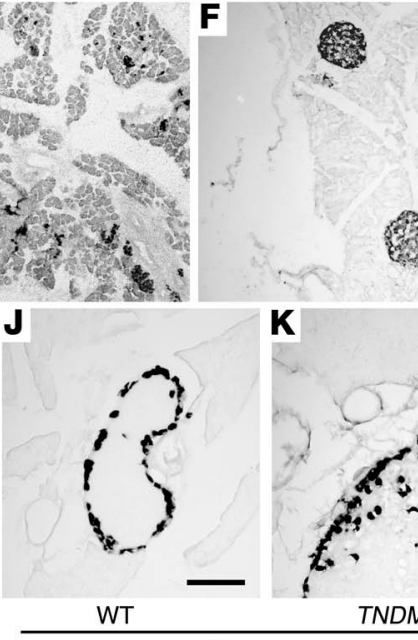

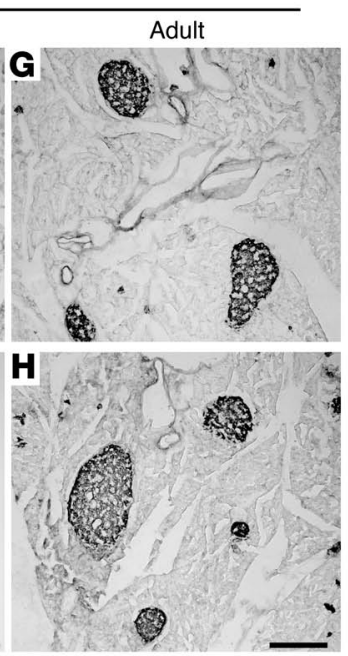

$\mathbf{L}$

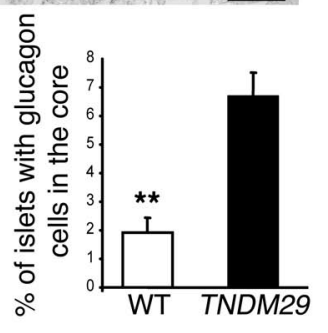



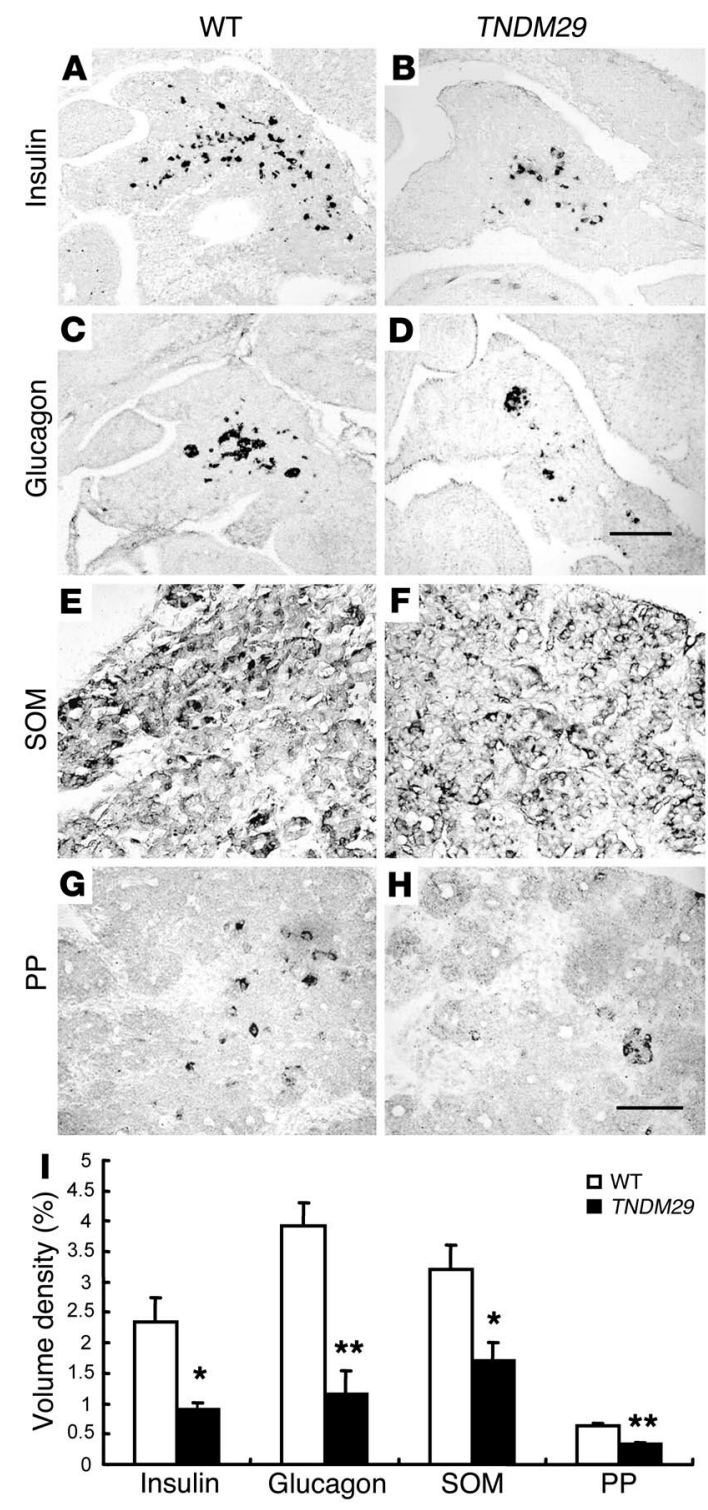

older adult TNDM29 mice. An analogous mechanism may contribute to the relapse into type 2 diabetes observed in late teenage years in human TNDM patients (1). Thus, despite some evidence in humans that insulin resistance may play a role in the relapse of affected patients to frank diabetes in later life, our clamp studies in mice found no decrease in peripheral insulin sensitivity. Further studies of human TNDM are required to clarify this issue.

Expression of regulators of pancreatic development in TNDM29 mice. Endocrine pancreas development involves the interplay of an array of transcription factors, hormones, growth factors, and nutrition $(28,32)$. The transcription factor PDX-1 $(33,34)$ plays an important role in pancreatic neogenesis and the differentiation of $\beta$ cells, while $\mathrm{Ngn} 3$ is a key proendocrine factor and a marker of endocrine precursor cells (35-38), and PAX6 is a marker of later progenitors, especially glucagon-producing cells (39-41). We show here that PDX-1 expression and the number of Ngn3- and PAX6-expressing cells is reduced within the embryonic pancreas of TNDM29 mice. Consistent with these deficits, there was a reduction in all four endocrine cell types in the embryonic pancreas of the transgenic mice.

\section{Figure 8}

Immunohistochemistry for hormone-producing cells in embryonic pancreata. Sagittal sections from 14.5-dpc embryos showing pancreas stained for insulin (A and B), glucagon ( $\mathbf{C}$ and $\mathbf{D})$, somatostatin (SOM; $\mathbf{E}$ and $\mathbf{F})$, and PP ( $\mathbf{G}$ and $\mathbf{H})$ in TNDM29 (B, D, F, and $\mathbf{H})$ and wild-type (A, $\mathbf{C}, \mathbf{E}$, and $\mathbf{G}$ ) littermates. (I) Volume density for the positive structures ( $n=3-5$ embryos per group). Results are expressed as mean \pm SEM; ${ }^{\star} P<0.05,{ }^{* *} P<0.01$ transgenic versus control group by unpaired, twotailed Student's $t$ test. Scale bars: $150 \mu \mathrm{m}$ (A-D); $40 \mu \mathrm{m}(\mathbf{E}-\mathbf{H})$.

Complete loss of PDX-1 expression in mice $(37,42-44)$ or inactivation of the orthologous IPF-1 (insulin promoter factor-1) gene in humans (45), results in the failure to develop a pancreas. Moreover, mice heterozygous for $P D X-1$ mutation display defective insulin release and are glucose intolerant $(46,47)$ whereas a transdominant mutation in the human IPF-1 gene leads to maturityonset diabetes of the young-4 (48). In adult mice, PDX-1 promotes the expression of proinsulin and Slc2a2 (solute carrier family 2, member 2; also termed Glut2 [glucose transporter type 2]), the latter playing a critical role in mediating glucose-stimulated insulin secretion $(49,50)$. The reduction in PDX-1 expression in TNDM29 mice not only could account for the defective development of the endocrine pancreas, but also suggests that PDX-1 could be a target gene of ZAC and/or HYMAI. In situ hybridization shows that these genes are expressed in ductal structures in embryonic pancreas, as is PDX-1. However, given that PDX-1 expression is itself controlled by upstream factors including hepatic nuclear factor $3 \alpha$ (HNF3 $\alpha$, or forkhead box O1 [FOXO1]) (51) and HNF3 $\beta$ (forkhead box $\mathrm{O} 2$ [FOXO2]) (52), the possibility cannot be excluded that the observed suppression of PDX-1 expression in TNDM29 mice may be the result of an indirect mechanism involving changes in the levels of these or other transcription factors.

Possible roles of the imprinted genes ZAC and HYMAI in TNDM. The TNDM interval has been defined from paternal duplications of $6 \mathrm{q} 24$ and is between $355 \mathrm{~kb}$ and $648 \mathrm{~kb}$ (ref. 8; D. Mackay, personal communication). Interestingly, a recent genome-wide scan has found evidence for a locus for type 2 diabetes mellitus on 6q24-q27, close to the TNMD interval, in African Americans (53); there is also weak evidence for an association of paternally derived alleles of $6 \mathrm{q}$ and type 2 diabetes in Pima Indians (54). The only known genes entirely located in the TNDM interval are ZAC, HYMAI and SYT11: only ZAC and HYMAI are imprinted and have been shown to have methylation anomalies in non-UPD/nonduplication TNDM patients $(8,13)$. ZAC and HYMAI are overlapping and initiate at the same differentially methylated CPG island $(15,55)$. Interestingly, both mRNAs were barely detectable in normal mouse islets by in situ hybridization but were easily detectable in exocrine pancreas, suggesting that the absence of one or both may be important for normal islet development. Although the present study did not seek to explore the relative importance of these two genes, because HYMAI generates an untranslated mRNA of unknown function $(11,15)$, its contribution to the diabetic phenotype in TNDM patients and TNDM29 mice is uncertain. By contrast, $Z A C$ encodes a zinc finger protein, which is a potential transcription regulator. In addition to its role in promoting apoptosis, ZAC has been shown to induce expression of the PAC1-R gene $(22,23)$. PAC1-R overexpression would seem likely to enhance, rather than diminish, glucose-induced insulin secretion in vivo and $\beta$ proliferation $(25,56,57)$, and PAC1-R-deficient mice display impaired glucose-induced insulin secretion and glucose intolerance (58). Correspondingly, islets isolated from neonatal TNDM29 trans- 

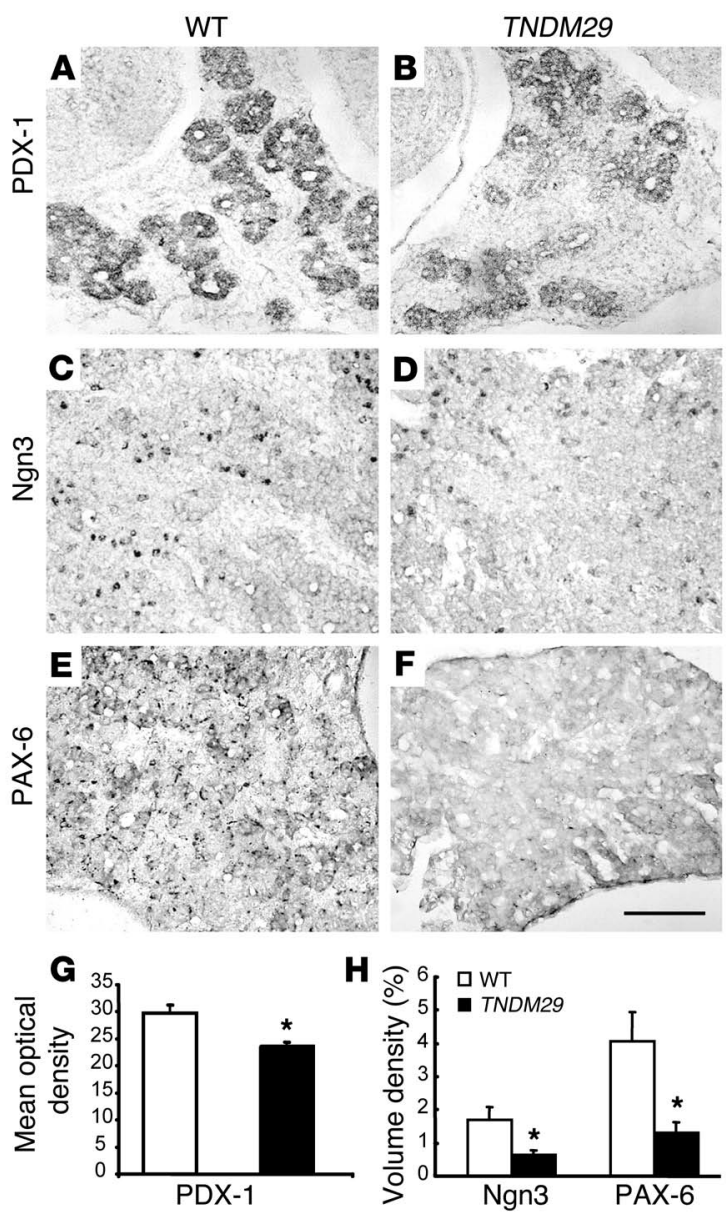

genic animals were more responsive to PACAP stimulation. However, PAC1-R is widely expressed in many tissues (57), consistent with a possible extrapancreatic contribution to the TNDM phenotype.

In conclusion, we describe here transgenic TNDM mice that develop abnormal glucose tolerance with a strikingly similar time course to affected humans. These animals should thus provide a useful tool for future studies of this condition.

\section{Methods}

Transgenic mice. The animal studies described in this article were carried out under the guidance issued by the Medical Research Council in Responsibility in the Use of Animals for Medical Research (July 1993) and United Kingdom Home Office Project Licence PPL 80/1467. DNA for the human PAC RP3-340H11 (gift of A. Mungall, Wellcome Trust Sanger Institute, Hinxton, United Kingdom) prepared using the QIAGEN large construct kit (QIAGEN Ltd., Crawley, United Kingdom) was linearized with BsiWI or $S f i$ prior to pronuclear injection into $\mathrm{F}_{1}(\mathrm{C} 57 \mathrm{BL} / 6 \mathrm{JxCBA} / \mathrm{Ca}) \times \mathrm{F}_{1}$ mouse oocytes. Transgenic founders identified by PCR for the markers J340H11T7 (primers: 5'-AGTCAATTTCACCAGAACCCC-3' and CTGGGGGAGGATGGAGAC), WI-11634 (5'-TTGATCTATTTAGTCAAGTCCAGCC-3' and TTCCCATTCCTCACAGCATT-3'), hZAC-CG (5'-GTTCGCGCCTATCTGGTATG-3' and 5'-CAGCTGTCCCGATCTAGGAA-3'), and SG9563 (5'-CTAAAAACATAAGACAATGGAG-3' and 5'-GTAATTCATCAGTCATTATTAGC-3'). Founders were backcrossed to C57BL/6J and transgenic lines established. Routine genotyping was done by PCR of lysates of tail biopsies for markers bZAC-CG and WI-11634. Southern blotting for transgene copy number determination employed a probe adjacent to

\section{Figure 9}

Immunohistochemistry for differentiation markers in embryonic pancreata. Sagittal sections from 14.5-dpc embryos showing pancreas stained for PDX-1 (A and B), Ngn3 (C and D), and PAX6 (E and F). (G) Intensity of PDX-1 staining in pancreas determined in wild-type and TNDM29 sections ( $n=4$ embryos per group). (H) Volume density for the positive structures ( $n=3$ embryos per group) of Ngn3 and PAX6. Results are expressed as mean $\pm \mathrm{SEM}$; ${ }^{*} P<0.05$ transgenic versus control group by unpaired, two-tailed Student's $t$ test. Scale bar: $80 \mu \mathrm{m}(\mathbf{A}-\mathbf{F})$.

the human ZAC CPG island (IMAGE 2073154), and was done on neonatal brain DNA samples of $10 \mu \mathrm{g}$ digested with HindIII. Transgenic lines TNDM29 and TNDM35 were maintained as hemizygotes by backcrossing with C57BL/6J, and analysis was carried out after 2-4 backcross generations. Nontransgenic progeny were used as controls throughout.

$R N A$ analysis by RT-PCR. Total RNA was obtained from tissues using the RNeasy Mini kit (QIAGEN), and RT-PCRs were performed as previously described (55). Primers for amplification of human $Z A C$ and mouse $Z a c$ were hmZAC-RTf (5'-CAATTATTCCCACTCCAGGG-3') and hmZAC-RTr (5'GGAAGTCCTTGCATCCTGTG-3'). PCR products were diluted threefold for digestion with StyI to discriminate products from human and mouse transcripts. Primers for amplification of human HYMAI were as described (14).

In situ bybridization. For postnatal stages, fresh tissue ( $n=3$ from transgenic and control groups) was frozen on dry ice, and cryostat sections (20 $\mu \mathrm{m})$ were cut (Bright Instruments Co., Huntingdon, United Kingdom); sections were either used immediately or stored at $-70^{\circ} \mathrm{C}$ for further use. Embryos ( $14.5 \mathrm{dpc} ; n=3$ for each group) were immersed in Bouin's fixative overnight at $4{ }^{\circ} \mathrm{C}$ and then paraffin embedded. Sections were cut at $7 \mu \mathrm{m}$ thickness. All sections were subsequently fixed in $4 \%$ paraformaldehyde in PBS prior to hybridization. Riboprobes were prepared from the following plasmids: human $Z A C$ corresponding to nucleotides $1878-2478$ of AJ006354 was subcloned from pBS-hZAC; mouse Zac corresponding to nucleotides 0-456 of NM009538 was subcloned from pBS-mZac1 (both originating plasmids being the kind gift of L. Journot, CNRS UPR 9023, Montpellier, France); human HYMAI was produced from IMAGE clone 2073154 (from the United Kingdom HMGP Resource Centre, Hinxton, United Kingdom); mouse Hymai was subcloned from clone CPGC\#27 (55) and corresponded to nucleotides 1-679 in AJ308560. Antisense and sense probes were synthesized by transcription with $\mathrm{T} 7$ or T3 RNA polymerase from plasmids linearized with appropriate restriction enzymes, and by use of a digoxigenin RNA labeling kit (Roche Diagnostics Ltd., Lewes, United Kingdom). In situ hybridization was performed as described (59) with minor modifications. Briefly, sections were prehybridized in hybridization buffer at $58^{\circ} \mathrm{C}$ for 2 hours and then hybridized at $58^{\circ} \mathrm{C}$ overnight with $0.8-1.0 \mu \mathrm{g} / \mathrm{ml}$ of the respective riboprobes. The slides were washed twice in $2 \times \mathrm{SSC}$ at $65^{\circ} \mathrm{C}$ for 30 minutes and then in $0.2 \times \mathrm{SSC}$ at $65^{\circ} \mathrm{C}$ for 1 hour. Sections were then incubated with antigen-binding fragments of alkaline phosphatase conjugated anti-digoxigenin antibody (1:2,000; Roche Diagnostics Ltd.). Precipitation of the reaction products of nitroblue tetrazolium/5-bromo-4-chloro-3-indolyl phosphate (Roche Diagnostics Ltd.) was allowed overnight at room temperature, in the presence of levamisole (Sigma-Aldrich, Poole, United Kingdom). Controls were performed by using sense probe, and no signal was detected.

Glucose and insulin measurements. Blood glucose levels were determined in whole blood immediately on collection with a Blood Glucose Analyzer (HemoCue Ltd., Dronfield, United Kingdom). For serum insulin determinations, blood samples collected by heart puncture were kept at room temperature for 3 hours and stored at $4{ }^{\circ} \mathrm{C}$ overnight. For neonates, blood and serum were collected after decapitation. Samples were centrifuged, and serum was separated and stored at $-20^{\circ} \mathrm{C}$. Insulin concentration was 
determined by radioimmunoassay using a Rat Insulin RIA Kit (RI-13K; Biogenesis Ltd., Poole, United Kingdom) for juvenile and adult samples or Ultra Sensitive Rat Insulin ELISA kit (Crystal Chem Inc., Downers Grove, Illinois, USA) for neonatal samples. For measurement of total pancreatic insulin, pancreata were removed and immediately frozen in dry ice. Insulin was extracted by mechanical homogenization in iced acid ethanol $(0.7 \mathrm{M}$ $\mathrm{HCl} /$ ethanol 25:75 plus 0.1\% Triton X-100). After 24 hours at $4^{\circ} \mathrm{C}$, samples were centrifuged and the supernatant collected and stored at $-20^{\circ} \mathrm{C}$. Hormone concentrations were determined by radioimmunoassay and total protein content by Bradford reagent (Sigma-Aldrich).

Glucose and insulin tolerance tests and hyperinsulinemic euglycemic clamps. For glucose tolerance tests, mice were fasted overnight and a single intraperitoneal injection of D-glucose (Sigma-Aldrich; $1 \mathrm{~g} / \mathrm{kg}$ body weight) together with sedative $(0.01 \mathrm{ml} / 30 \mathrm{~g}$ body weight Hypnorm; Janssen-Cilag Ltd., Saunderton, United Kingdom) was given. Blood samples for glucose analysis were withdrawn from the cut tail end before and at the indicated times after glucose injection. For insulin tolerance, mice fed ad libitum were injected intraperitoneally with $1 \mathrm{U} / \mathrm{kg}$ insulin (Sigma-Aldrich) together with Hypnorm, and blood samples were taken as above. For neonates (which were not fasted), a single terminal blood sampling was made after decapitation at 0 minutes, 30 minutes, or 120 minutes after glucose or insulin injection. Hyperinsulinemic euglycemic clamps were performed as previously described $(60,61)$, using adult (7-month-old) female mice $(n=5$ TNDM group, $n=6$ in control group).

Isolation of pancreatic islets and insulin secretion assays. Islets were isolated by digestion of pancreata with collagenase V (Sigma-Aldrich), as described elsewhere (62). Insulin secretion from 5-7 islets per assay tube was measured, after incubation of islets in Kreb's Ringer-based medium containing $3 \mathrm{mM}$, then $17 \mathrm{mM}$ glucose, and then in the presence of 0.1 $\mu$ M PACAP-38 (Bachem [UK] Ltd., St. Helens, United Kingdom), for 25 minutes for each incubation condition. Secreted and total islet insulin were measured by radioimmunoassay (63).

Immunohistochemistry. Adult transgenic and control mice ( $n=5$ each) were perfused with $4 \%$ paraformaldehyde in PBS and the tissues were then fixed for 2 hours. Neonatal pancreata $(n=5$ each) were directly dissected out and fixed in the same fixative for 2 hours at room temperature. After sucrose treatment, tissues were sectioned by cryostat at $20 \mu \mathrm{m}$ thickness. Embryos $(14.5 \mathrm{dpc} ; n=5)$ were treated and sectioned as for in situ hybridization. Both cryostat and paraffin-embedded sections were incubated overnight at $4^{\circ} \mathrm{C}$ with primary antibodies: guinea pig anti-porcine insulin antibody (DAKO UK Ltd., Ely, United Kingdom) diluted 1:100; monoclonal anti-rat glucagon antibody (Sigma-Aldrich) diluted 1:4000; polyclonal anti-PDX-1 antibody (64) diluted 1:50; monoclonal anti-chick PAX6 antibody (Developmental Studies Hybridoma Bank, Iowa, USA) diluted 1:100; rabbit anti-Ngn 3 antibody (65) diluted 1:4000; rat anti-somatostatin monoclonal antibody (CHEMICON International Inc., Temecula, California, USA) diluted 1:100; and rabbit anti-PP antibody (Novocastra Laboratories Ltd., Newcastleupon-Tyne, United Kingdom) diluted 1:500. Detections were done using biotinylated secondary antibodies and avidin-biotin complex (ABC; Vector Laboratories Ltd., Peterborough, United Kingdom), with 3'3'-diaminobenzidine (Sigma-Aldrich) as chromogen, with the nickel and glucose oxidase method for enhancement. For PDX-1, PAX6, and Ngn3, antigen retrieval was carried out before incubation with the primary antibodies by treating the sections in $10 \mathrm{mM}$ citrate buffer $\mathrm{pH} 6.0$ at $95^{\circ} \mathrm{C}$ for 15 minutes.
Morphometric analysis. Pancreata of transgenic mice and controls $(n=5)$ of different age groups were obtained and serially sectioned as above. H\&E staining and immunohistochemical detection of insulin and glucagon were each performed on 1 in 5 serial sections. The average radius of $\beta$ cells (hence the size) was obtained by measuring the distance between 2 adjacent nuclei of cells randomly chosen by grids on H\&E-stained sections. The islet area $\left(\mathrm{mm}^{2}\right)$ and the area of each pancreatic section were determined by use of image analysis software (Leica Qwin; Leica Microsystems [UK] Ltd, Milton Keynes, United Kingdom), or grids for measuring points hitting the islet and whole pancreas. Similar methods were applied to quantitation of other immunohistochemical positive structures. The ratio of total islet area to area of whole set of sections from each mouse was obtained by representing the volume density of the islets in the pancreas. The pancreas weight was measured and presented as pancreatic/body weight, the ratios in transgenic and control groups being similar $(P=0.8)$, such that the volume density of islets represents the total volume and mass of islets. Glucagonpositive cell distribution was determined by counting the percentage of the islets in which there were glucagon-positive cells in the islet core, if one or more glucagon-positive cells were present at a distance of more than four cell diameters from the islet periphery. More than 100 target items were counted for each parameter per mouse. PDX-1-immunostaining intensity was determined using Scion Image (NIH, Bethesda, Maryland, USA) after circling regions of positive labeling and measurement of optical density.

Statistical analysis. All values are expressed as mean \pm SEM. Statistical analysis was carried out using the unpaired Student's $t$ test, chi-squared test or Mann Whitney $U$ test, and correlation coefficient, as appropriate. Differences were considered statistically significant at $P<0.05$.

\section{Acknowledgments}

We thank Sue Ozanne and Jane Goode for technical advice; Gabriela da Silva Xavier for help in setting up islet isolation; Galia Konfortova for preparation of histological slides; and Eurof Walters for help with statistical analysis. We are grateful to Laurent Journot for human ZAC and mouse Zac cDNAs, Andy Mungall for PAC RP3-340H11, and David Scheel for the Ngn3 antibody. We also thank members of The Babraham Institute Small Animal Barrier Unit for animal husbandry. D. Ma was a Research Fellow of Clare Hall, Cambridge. J.P.H. Shield received support from Diabetes UK to study Neonatal Diabetes. G.A. Rutter was supported by a Wellcome Trust Research Leave Fellowship and grants from the Wellcome Trust, the Medical Research Council (United Kingdom), Diabetes UK, and the Juvenile Diabetes Research Fund International. I. Leclerc is a Wellcome Trust Advanced Fellow. G. Kelsey is a Senior Fellow of the Medical Research Council (United Kingdom) and is supported by the Biotechnology and Biological Sciences Research Council.

Received for publication August 22, 2003, and accepted in revised form May 25, 2004.

Address correspondence to: Gavin Kelsey, Developmental Genetics Programme, The Babraham Institute, Cambridge CB2 4AT, United Kingdom. Phone: 44-1223-496332; Fax: 44-1223-496022; E-mail: gavin.kelsey@bbsrc.ac.uk.
1. Shield, J.P., et al. 1997. Aetiopathology and genetic basis of neonatal diabetes. Arch. Dis. Child Fetal Neonatal Ed. 76:F39-F42.

2. Temple, I.K., et al. 2000. Transient neonatal diabetes: widening the understanding of the etiopathogenesis of diabetes. Diabetes. 49:1359-1366.

3. Shield, J.P., et al. 2001. Variable evidence of pancre- atic insufficiency in those children with transient neonatal diabetes mellitus in remission. Pediatr. Res. 49(Suppl. P2):619.

4. Blum, D., et al. 1993. Congenital absence of insulin cells in a neonate with diabetes mellitus and mutase-deficient methylmalonic acidaemia. Diabetologia. 36:352-357.
5. Shield, J.P., and Baum, J.D. 1995. Transient neonatal diabetes and later onset diabetes: a case of inherited insulin resistance. Arch. Dis. Child. 72:56-57.

6. Temple, I.K., et al. 1995. An imprinted gene(s) for diabetes? Nat. Genet. 9:110-112.

7. Temple, I.K., et al. 1996. Further evidence for an imprinted gene for neonatal diabetes localised to chro- 
mosome 6q22-q23. Hum. Mol. Genet. 5:1117-1121.

8. Gardner, R.J., et al. 2000. An imprinted locus associated with transient neonatal diabetes mellitus. Hum. Mol. Genet. 9:589-596.

9. Surani, M.A. 2001. Reprogramming of genome function through epigenetic inheritance. Nature. 414:122-128.

10. Reik, W., and Walter, J. 2001. Genomic imprinting: parental influence on the genome. Nat. Rev. Genet. 2:21-32.

11. Arima, T., Drewell, R.A., Oshimura, M., Wake, N., and Surani, M.A. 2000. A novel imprinted gene, HYMAI, is located within an imprinted domain on human chromosome 6 containing ZAC. Genomics. 67:248-255.

12. Kamiya, M., et al. 2000. The cell cycle control gene ZAC/PLAGL1 is imprinted - a strong candidate gene for transient neonatal diabetes. Hum. Mol. Genet. 9:453-460.

13. Varrault, A., et al. 2001. Characterization of the methylation-sensitive promoter of the imprinted ZAC gene supports its role in transient neonatal diabetes mellitus. J. Biol. Chem. 276:18653-18656.

14. Mackay, D.J., et al. 2002. Relaxation of imprinted expression of ZAC and HYMAI in a patient with transient neonatal diabetes mellitus. Hum. Genet. 110:139-144

15. Arima, T., et al. 2001. A conserved imprinting control region at the HYMAI/ZAC domain is implicated in transient neonatal diabetes mellitus. Hum Mol. Genet. 10:1475-1483.

16. Spengler, D., et al. 1997. Regulation of apoptosis and cell cycle arrest by Zac1, a novel zinc finger protein expressed in the pituitary gland and the brain. EMBO J. 16:2814-2825.

17. Varrault, A., et al. 1998. hZAC encodes a zinc finger protein with antiproliferative properties and maps to a chromosomal region frequently lost in cancer Proc. Natl. Acad. Sci. U. S. A. 95:8835-8840.

18. Abdollahi, A., et al. 1997. Identification of a gene containing zinc-finger motifs based on lost expression in malignantly transformed rat ovarian surface epithelial cells. Cancer Res. 57:2029-2034.

19. Kas, K., Voz, M.L., Hensen, K., Meyen, E., and Van de Ven, W.J. 1998. Transcriptional activation capacity of the novel PLAG family of zinc finger proteins J. Biol. Chem. 273:23026-23032.

20. Huang, S.M., and Stallcup, M.R. 2000. Mouse Zac1, a transcriptional coactivator and repressor for nuclear receptors. Mol. Cell. Biol. 20:1855-1867.

21. Hoffmann, A., et al. 2003. Transcriptional activities of the zinc finger protein Zac are differentially controlled by DNA binding. Mol. Cell. Biol. 23:988-1003

22. Ciani, E., Hoffmann, A., Schmidt, P., Journot, L., and Spengler, D. 1999. Induction of the PAC1-R (PACAP-type I receptor) gene by $\mathrm{p} 53$ and Zac. Brain Res. Mol. Brain Res. 69:290-294.

23. Rodriguez-Henche, N., Jamen, F., Leroy, C., Bockaert, J., and Brabet, P. 2002. Transcription of the mouse PAC1 receptor gene: cell-specific expression and regulation by Zac1. Biochim. Biophys. Acta. 1576:157-162.

24. Filipsson, K., Kvist-Reimer, M., and Ahren, B. 2001 The neuropeptide pituitary adenylate cyclase-activating polypeptide and islet function. Diabetes. 50:1959-1969.

25. Yamamoto, K., et al. 2003. Overexpression of PACAP in transgenic mouse pancreatic beta-cells enhances insulin secretion and ameliorates streptozotocin-induced diabetes. Diabetes. 52:1155-1162.

26. Weir, S.B. 1989. Pancreatic islets: morphology, organization and physiological implication. Molec ular and Cellular Biology of Diabetes Mellitus. 1:1-11.
27. Madsen, O.D., et al. 1996. Pancreatic development and maturation of the islet B cell. Studies of pluripotent islet cultures. Eur. J. Biochem. 242:435-445.

28. Slack, J.M. 1995. Developmental biology of the pancreas. Development. 121:1569-1580.

29. Bonner-Weir, S. 2000. Perspective: Postnatal pancreatic beta cell growth. Endocrinology. 141:1926-1929.

30. Swenne, I. 1985. Glucose-stimulated DNA replication of the pancreatic islets during the development of the rat fetus. Effects of nutrients, growth hormone, and triiodothyronine. Diabetes. 34:803-807.

31. Finegood, D.T., Scaglia, L., and Bonner-Weir, S. 1995. Dynamics of beta-cell mass in the growing rat pancreas. Estimation with a simple mathematical model. Diabetes. 44:249-256.

32. Sander, M., and German, M.S. 1997. The beta cell transcription factors and development of the pancreas. J. Mol. Med. 75:327-340.

33. McKinnon, C.M., and Docherty, K. 2001. Pancreatic duodenal homeobox-1, PDX-1, a major regulator of beta cell identity and function. Diabetologia. 44:1203-1214

34. Melloul, D., Marshak, S., and Cerasi, E. 2002. Regulation of $\mathrm{pdx}-1$ gene expression. Diabetes. 51 (Suppl. 3):S320-S325.

35. Lee, J.C., et al. 2001. Regulation of the pancreatic proendocrine gene neurogenin3. Diabetes. 50:928-936.

36. Gradwohl, G., Dierich, A., LeMeur, M., and Guillemot, F. 2000. Neurogenin 3 is required for the development of the four endocrine cell lineages of the pancreas. Proc. Natl. Acad. Sci. U. S. A. 97:1607-1611.

37. Gu, G., Dubauskaite, J., and Melton, D.A. 2002. Direct evidence for the pancreatic lineage: NGN3+ cells are islet progenitors and are distinct from duct progenitors. Development. 129:2447-2457.

38. Herrera, P.L., Nepote, V., and Delacour, A. 2002. Pancreatic cell lineage analyses in mice. Endocrine. 19:267-278.

39. Dohrmann, C., Gruss, P., and Lemaire, L. 2000. Pax genes and the differentiation of hormone-producing endocrine cells in the pancreas. Mech. Dev. 92:47-54.

40. Sander, M., et al. 1997. Genetic analysis reveals that PAX6 is required for normal transcription of pancreatic hormone genes and islet development. Genes Dev. 11:1662-1673.

41. St-Onge, L., Sosa-Pineda, B., Chowdhury, K., Mansouri, A., and Gruss, P. 1997. Pax6 is required for differentiation of glucagon-producing alpha-cells in mouse pancreas. Nature. 387:406-409.

42. Jonsson, J., Carlsson, L., Edlund, T., and Edlund, H. 1994. Insulin-promoter-factor 1 is required for pancreas development in mice. Nature. 371:606-609.

43. Ahlgren, U., Jonsson, J., and Edlund, H. 1996. The morphogenesis of the pancreatic mesenchyme is uncoupled from that of the pancreatic epithelium in IPF1/PDX1-deficient mice. Development. 122:1409-1416

44. Gannon, M., Herrera, P.L., and Wright, C.V. 2000 Mosaic Cre-mediated recombination in pancreas using the pdx-1 enhancer/promoter. Genesis. 26:143-144

45. Stoffers, D.A., Zinkin, N.T., Stanojevic, V., Clarke, W.L., and Habener, J.F. 1997. Pancreatic agenesis attributable to a single nucleotide deletion in the human IPF1 gene coding sequence. Nat. Genet. 15:106-110.

46. Dutta, S., Bonner-Weir, S., Montminy, M., and Wright, C. 1998. Regulatory factor linked to lateonset diabetes? Nature. 392:560. (Letter)

47. Offield, M.F., et al. 1996. PDX-1 is required for pancreatic outgrowth and differentiation of the rostral duodenum. Development. 122:983-995.

48. Stoffers, D.A., Ferrer, J., Clarke, W.L., and Haben- er, J.F. 1997. Early-onset type-II diabetes mellitus (MODY4) linked to IPF1. Nat. Genet. 17:138-139.

49. Rutter, G.A. 2001. Nutrient-secretion coupling in the pancreatic islet beta-cell: recent advances. Mol. Aspects Med. 22:247-284

50. Hui, H., and Perfetti, R. 2002. Pancreas duodenum homeobox-1 regulates pancreas development during embryogenesis and islet cell function in adulthood. Eur. J. Endocrinol. 146:129-141.

51. Kitamura, T., et al. 2002. The forkhead transcription factor Foxo1 links insulin signaling to Pdx1 regulation of pancreatic beta cell growth. J. Clin. Invest. 110:1839-1847. doi:10.1172/JCI200216857.

52. Gerrish, K., et al. 2000. Pancreatic beta cell-specific transcription of the pdx-1 gene. The role of conserved upstream control regions and their hepatic nuclear factor 3beta sites. J. Biol. Chem. 275:3485-3492.

53. Sale, M.M., et al. 2004. A genome-wide scan for type 2 diabetes in african-american families reveals evidence for a locus on chromosome 6q. Diabetes. 53:830-837.

54. Lindsay, R.S., Kobes, S., Knowler, W.C., Bennett, P.H., and Hanson, R.L. 2001. Genome-wide linkage analysis assessing parent-of-origin effects in the inheritance of type 2 diabetes and BMI in Pima Indians. Diabetes. 50:2850-2857.

55. Smith, R.J., et al. 2002. The mouse Zac1 locus: basis for imprinting and comparison with human ZAC. Gene. 292:101-112.

56. Borboni, P., et al. 1999. Molecular and functional characterization of pituitary adenylate cyclase-activating polypeptide (PACAP-38)/vasoactive intestinal polypeptide receptors in pancreatic beta-cells and effects of PACAP- 38 on components of the insulin secretory system. Endocrinology. 140:5530-5537.

57. Vaudry, D., et al. 2000. Pituitary adenylate cyclaseactivating polypeptide and its receptors: from structure to functions. Pharmacol. Rev. 52:269-324.

58. Jamen, F., et al. 2000. PAC1 receptor-deficient mice display impaired insulinotropic response to glucose and reduced glucose tolerance. J. Clin. Invest. 105:1307-1315

59. Braissant, O., and Wahli, W. 1998. A simplified in situ hybridisation protocol using non-radioactively labeled probes to detect abundant and rare mRNAs on tissue sections. Biochemica. 1:10-16.

60. Burcelin, R., Crivelli, V., Dacosta, A., Roy-Tirelli, A., and Thorens, B. 2002. Heterogeneous metabolic adaptation of C57BL/6J mice to high-fat diet. Am. J. Physiol. Endocrinol. Metab. 282:E834-E842.

61. Burcelin, R., et al. 2003. GLUT4, AMP kinase, but not the insulin receptor, are required for hepatoportal glucose sensor-stimulated muscle glucose utilization. J. Clin. Invest. 111:1555-1562. doi:10.1172/JCI200316888.

62. Jonas, J.C., Gilon, P., and Henquin, J.C. 1998. Temporal and quantitative correlations between insulin secretion and stably elevated or oscillatory cytoplasmic Ca2 + in mouse pancreatic beta-cells. Diabetes. 47:1266-1273.

63. Ainscow, E.K., Zhao, C., and Rutter, G.A. 2000. Acute overexpression of lactate dehydrogenase-A perturbs beta-cell mitochondrial metabolism and insulin secretion. Diabetes. 49:1149-1155.

64. Rafiq, I., da Silva Xavier, G., Hooper, S., and Rutter, G.A. 2000. Glucose-stimulated preproinsulin gene expression and nuclear trans-location of pancreatic duodenum homeobox-1 require activation of phosphatidylinositol 3-kinase but not p38 MAPK/ SAPK2. J. Biol. Chem. 275:15977-15984.

65. Schwitzgebel, V.M., et al. 2000. Expression of neurogenin3 reveals an islet cell precursor population in the pancreas. Development. 127:3533-3542. 